\title{
Evaluation of Neuroprotective Effect of Thymoquinone Nanoformulation in the Rodent Cerebral Ischemia-Reperfusion Model
}

\author{
Xiao-Yu Xiao, ${ }^{1}$ Ying-Xian Zhu, ${ }^{1}$ Ju-Yuan Bu, ${ }^{2}$ Guo-Wei Li, ${ }^{3}$ \\ Jian-Hui Zhou, ${ }^{4}$ and Shao-Peng Zhou ${ }^{1}$ \\ ${ }^{1}$ Department of Anaesthesiology, Fifth Affiliated Hospital, Sun Yat-Sen University, Zhuhai, Guangdong 519000, China \\ ${ }^{2}$ Department of Gastrointestinal Surgery, Fifth Affiliated Hospital, Sun Yat-Sen University, Zhuhai, Guangdong 519000, China \\ ${ }^{3}$ Department of Spine Surgery, Fifth Affiliated Hospital, Sun Yat-Sen University, Zhuhai, Guangdong 519000, China \\ ${ }^{4}$ Department of Laboratory, Fifth Affiliated Hospital, Sun Yat-Sen University, Zhuhai, Guangdong 519000, China \\ Correspondence should be addressed to Shao-Peng Zhou; zhoushaopeng21@hotmail.com
}

Received 9 April 2016; Accepted 10 July 2016

Academic Editor: Sanjula Baboota

Copyright (C) 2016 Xiao-Yu Xiao et al. This is an open access article distributed under the Creative Commons Attribution License, which permits unrestricted use, distribution, and reproduction in any medium, provided the original work is properly cited.

\begin{abstract}
The purpose of the present study was to evaluate the neuroprotective efficacy of optimized thymoquinone loaded PLGA-chitosan nanoparticles delivered via nose to brain route in the rodent cerebral ischemia-reperfusion model. The neuroprotective efficacy of the optimized thymoquinone loaded PLGA-chitosan nanoparticles was evaluated in middle cerebral artery occluded rats by various pharmacodynamic and biochemical studies. The pharmacokinetics of thymoquinone loaded PLGA-chitosan nanoparticles in the brain and blood plasma together with qualitative localization of florescent labelled PLGA-chitosan nanoparticles in brain tissues were also determined. Intranasal delivery of optimized thymoquinone loaded PLGA-chitosan nanoparticles $(183.5 \pm 8.2 \mathrm{~nm}, 33.63 \pm$ $2.25 \mathrm{mV}$ ) to brain significantly reduced the ischemia infarct volume and enhanced the locomotor activity and grip strength in the middle cerebral artery occluded rats. Biochemical studies showed that intranasal delivery of thymoquinone loaded PLGA-chitosan nanoparticles significantly reduced the lipid peroxidation but elevated the glutathione, catalase, and superoxide dismutase in the brain of middle cerebral artery occluded rats. The pharmacokinetic and localization studies showed that thymoquinone loaded PLGA-chitosan nanoparticles facilitated the delivery of thymoquinone to brain by intranasal nose to brain transport pathways and enhanced their pharmacokinetic profile in brain tissues. Thus, intranasal delivery of thymoquinone loaded PLGA-chitosan nanoparticles to brain could be potentially used for the neuroprotection and treatment of cerebral ischemia.
\end{abstract}

\section{Introduction}

Stroke is among the most leading causes of disability and death worldwide [1]. According to published reports, 1 in 6 persons will suffer at least one stroke in their lifetime which would cause death or disability and have magnanimous financial impact on health systems worldwide $[1,2]$. About $80 \%$ of these strokes are due to cerebral ischemia caused by embolic or nonembolic occlusion of a vital cerebral artery triggering the neuronal death, cerebral damage, morbidity, and mortality $[2,3]$. Further, there is large clinical variability in these strokes in terms of severity of ischemia, localization, duration, and causes which continue to make it one of the most challenging CNS diseases. The ischemia-reperfusion injury in brain has been found to produce large quantities of reactive oxygen species (ROS, e.g., hydroxyl radical, superoxide, peroxynitrite, and hydrogen peroxide) leading to oxidative stress which aggravates the damage done by cerebral ischemia [2-4]. As tissues of brain are more vulnerable to oxidative damage, pharmacological intervention for oxidative damage has been found to have promising role in ischemia stroke therapy [4]. In recent years, thymoquinone (TQ) extracted from seeds of Nigella sativa (Ranunculaceae) has been discovered to diminish ROS-mediated reactions 
and save the neurons from reperfusion-induced neuronal damage in rodents $[5,6]$. However, the brain delivery of these phytochemicals had been challenging as the presence of blood brain barrier (BBB) and blood-cerebrospinal fluid barrier prevents the free circulation of drug between blood and the central nervous system (CNS) [7]. Although these barriers are vital for normal physiological functions of the brain and spinal cord, they also present a significant hurdle in the treatment of various brain disorders [7]. These barriers also restrict the efficacy of different potential drug delivery systems delivered by oral, intravenous, transdermal, and other routes $[7,8]$. In past few years, intranasal (i.n.) nose to brain delivery has emerged as a novel noninvasive technique for transporting therapeutic agents to the CNS $[8,9]$. Nose to brain drug delivery is possible due to unique connection provided by the olfactory and/or trigeminal nerve system present between the olfactory epithelium and the CNS, bypassing the BBB $[8,9]$. Recently, a large number of publications have reported the nose to brain delivery of many drugs due to its obvious benefits, for example, avoidance of $\mathrm{BBB}$ and hepatic first pass metabolism, noninvasiveness, and ease of administration [8-11].

The objective of the present research work was to formulate a nanosized drug delivery system of TQ for evaluation of its neuroprotective efficacy in cerebral ischemia-reperfusion in rats. An additional aim of the current study was to determine the pharmacokinetics and brain localization of nose to brain delivered thymoquinone loaded PLGA NPs (TQPLGA NPs). For development of drug delivery system, polymeric nanoparticles composed of poly(lactide-co-glycolide) (PLGA) and chitosan (CN) were chosen because of their mucoadhesiveness, low systemic toxicity, biodegradability, and ability to encapsulate hydrophobic moieties. The neuroprotective efficacy of TQ-PLGA NPs was evaluated in middle cerebral artery occluded rats by pharmacodynamic and biochemical studies together with infarct volume estimation. The pharmacokinetics of TQ-PLGA NPs were determined by analyzing the levels of TQ in brain and blood plasma at various time intervals. The brain localization of PLGAchitosan nanoparticles (florescent labelled) was determined by confocal microscopy.

\section{Materials and Methods}

2.1. Materials. Carboxylic acid terminated PLGA (50:50, MW 9-12 KDa) was purchased from Shandong Institute of Medical Instrument (Jinan, Shandong, China). TQ was obtained from Chengdu Kaijie Biopharm Co., Ltd. (Chengdu, China). Polyvinyl alcohol (PVA, MW $30-70 \mathrm{kDa}$ ) and low MW CN ( $\sim 80 \%$ degree of deacetylation) were purchased from Sigma Chemical Co. All the other chemicals and reagents used were of the analytical grade.

2.2. Animals. Adult male Wistar rats $(300-350 \mathrm{~g})$ were selected for the in vivo studies. The current study was approved by the Research Review and Ethics Board (RREB), Sun Yat-Sen University, China (approval number: SYSU/ 2013/203), and all experiments were performed in accordance with the national institutes of health guide for the care and use of laboratory animals.

2.3. Preparation of Thymoquinone Loaded PLGA Nanoparticles. TQ-PLGA NPs were prepared by emulsion solvent evaporation method [12]. Briefly, $100 \mathrm{mg}$ of PLGA was dissolved in $1.5 \mathrm{~mL}$ of dichloromethane with or without TQ $(20 \% \mathrm{w} / \mathrm{w})$ and added to $15 \mathrm{~mL}$ aqueous phase containing $0.25 \%$ PVA and $0.25 \% \mathrm{CN}$. Since CN alone is unable to stabilize the PLGA nanoparticles, blend of CN and PVA was used for preparation of PLGA-CN nanoparticles [12]. The primary emulsion was vortexed for $90 \mathrm{sec}$ and then sonicated by a probe sonicator at $50 \mathrm{~W}$ (Q700 Sonicator, CT USA) for 60 seconds on ice. The organic solvents were evaporated using rotary evaporation (Rotavapor R-124, Buchi, Switzerland) and NPs were freeze-dried using mannitol as cryoprotectant $(2.5 \% \mathrm{w} / \mathrm{w})$.

2.4. Characterization of Thymoquinone Loaded PLGA Nanoparticles. TQ-PLGA NPs were characterized for different physiochemical properties such as particle size, size distribution, and zeta potential using Zetasizer (model: Nano ZS, Malvern Instruments, UK). The entrapment efficiency (EE) and loading capacity (LC) were determined by the separation of free TQ from the TQ-PLGA NPs by using a $100 \mathrm{kDa}$ cutoff Millipore membrane filter (Millipore Corp., $\mathrm{MA}) . \mathrm{EE} \%$ and $\mathrm{LC} \%$ were calculated using the following equations:

$$
\begin{aligned}
& \mathrm{EE} \%=\frac{(\text { total TQ }- \text { free TQ })}{\text { Total TQ }} \times 100, \\
& \mathrm{LC} \%=\frac{(\text { total TQ }- \text { free TQ })}{\text { weight of TQ-PLGA NPs }} \times 100 .
\end{aligned}
$$

Differential scanning calorimetry (DSC) analysis of PLGA polymer, TQ, physical mixture of polymer + drug (1:1), and freeze-dried TQ-PLGA NPs was done by PerkinElmer DSC-7 ${ }^{\circledR}$ (PerkinElmer, Inc., MA, USA). Equal weight of each sample was loaded on the standard aluminium pan and crimped. The crimped aluminium pans were heated under continuous nitrogen purging $(20 \mathrm{~mL} /$ minute $)$ at a heating rate of $5^{\circ} \mathrm{C} /$ minute to $350^{\circ} \mathrm{C}$. An empty crimped aluminium pan served as reference.

The in vitro release of TQ from optimized formulation was determined by dialysis bag (MWCO $12 \mathrm{KDa}$; SigmaAldrich) dipped in a dissolution apparatus filled with phosphate buffer $\left(\mathrm{pH} 7.4,37^{\circ} \mathrm{C} \pm 0.5^{\circ} \mathrm{C}\right)$. At predetermined sampling time points, a $2 \mathrm{~mL}$ aliquot was withdrawn for analysis and replaced with equal amount of fresh phosphate buffer till $24 \mathrm{~h}$. The samples were analyzed using reversephase HPLC with UV detection at $254 \mathrm{~nm}$ using mobile phase water : methanol : 2-propanol $(50: 45: 5)$ [13].

2.5. Mucoadhesive Potency of Nanoparticles. The mucoadhesive potency of nanoparticles and the TQ solution was determined by their mucin binding efficacy as described by Yin and associates [14]. Briefly, $2 \mathrm{~mL}$ of porcine mucin suspension $(0.5 \mathrm{mg} / \mathrm{mL})$ in phosphate buffer $(\mathrm{pH} 7.4)$ was incubated with same volume of nanoparticle suspension or 
TQ solution at $37^{\circ} \mathrm{C}$ for $60 \mathrm{~min}$. After the incubation period, the samples were centrifuged at $60000 \times \mathrm{g}$ for $30 \mathrm{~min}$. The free mucin in the supernatant was measured by UV spectrometry $(251 \mathrm{~nm})$ and the mucin binding efficiency was determined by the following equation:

mucin binding efficacy (\%)

$$
=\frac{(\text { total mucin }- \text { unassociated mucin })}{\text { total mucin }} \times 100 \text {. }
$$

\subsection{Pharmacodynamic Study}

2.6.1. Animals and Grouping. Rats were subdivided into five groups with 12 rats in each group. Groups 1 and 2 were the sham control and MCAO control, respectively. Group 2 and 3 rats were given TQ-PLGA NPs and TQ solution (equivalent to $5 \mathrm{mg} / \mathrm{kg} /$ day TQ) intranasally for 12 days, respectively. Group 4 was given TQ solution orally for 12 days. The dosing of different formulations was started 5 days prior to the $\mathrm{MCAO}$ and continued during the 7-day reperfusion time. The intranasal doses $(50 \mu \mathrm{L}$ in each nostril) were given to rats after mildly anaesthetising them under isoflurane. Rats were placed in a supine posture and the doses were instilled with the help of micropipette attached with the polyethylene tube $(0.1 \mathrm{~mm})$ positioned $5 \mathrm{~mm}$ deep in each nostril $[10,11]$.

\subsubsection{Middle Cerebral Artery Occlusion (MCAO) Surgery.} The middle cerebral artery occlusion (MCAO) model was used to evaluate the efficacy of intranasal TQ-PLGA NPs for the neuroprotection and treatment of cerebral ischemia [15]. Amongst many cerebral ischemic stroke models, the intraluminal suture MCAO in rodents, in particular rats, is the most regularly used because it can be used to produce permanent and/or transient ischemia in a very simple manner $[15,16]$. Cerebral ischemia in rats was induced by occlusion of middle cerebral artery for $2 \mathrm{~h}$ followed by 7 days of reperfusion. Briefly, under an observation microscope, an incision was made in the middle of the neck on ventral side and the external carotid artery, right common carotid artery, and the internal carotid artery were secluded from surrounding tissues. A blunted 4.0 silicon coated nylon monofilament (Doccol Corporation, Pennsylvania Avenue, USA) was inserted into the external carotid artery and slowly pushed towards the middle cerebral artery via the lumen of internal carotid artery until slight resistance was observed, which indicates the occlusion of middle cerebral artery [15]. The rats of sham control underwent all the surgical procedures except the MCAO. The nylon filament was slowly withdrawn after $2 \mathrm{~h}$ of induction of ischemia.

2.6.3. Behaviour Activity. After the reperfusion period, the locomotor activity and grip strength were assessed in different groups of animals. For measurement of locomotor activity, each rat was monitored for $5 \mathrm{~min}$ by digital photoactometer equipped with infrared light sensitive photocells in a light and sound attenuated room. For measurement of grip strength, the force generated by animal on detaching its front paws from the grid of grip strength meter was recorded and expressed in kilogram unit. After the assessment of neurobehavioral parameters, the animals were sacrificed for determination of ischemia infract volume and biochemical parameters in brain.

2.6.4. Infarct Volume Estimation. The infract volume was measured by a simple staining method described by Bederson et al. [17]. Briefly, rat brain was divided into $2 \mathrm{~mm}$ thick slide using microtome and treated with triphenyltetrazolium chloride (TTC, $2 \% \mathrm{w} / \mathrm{v}$ ) for $30 \mathrm{~min}$ at $37^{\circ} \mathrm{C}$. The tissue slides were then fixed with $4 \% \mathrm{w} / \mathrm{v}$ formaldehyde solution. The regions of the slides without the brick red colour (dark colour) of healthy brain tissue were considered infracted and expressed in $\mathrm{mm}^{3}$.

2.7. Biochemical Estimation. Following the pharmacodynamic tests, the animals were decapitated and the brains were quickly removed, weighed, washed with normal saline, and stored at $-80^{\circ} \mathrm{C}$ till further analysis. Brains were homogenized to a final concentration of $10 \% \mathrm{w} / \mathrm{v}$ using ice cold KCI phosphate buffer $(0.1 \mathrm{M} \mathrm{pH}$ 7.4). The first supernatant $\left(2000 \mathrm{rpm}\right.$ for $5 \mathrm{~min}$ at $4^{\circ} \mathrm{C}$ ) was used for determination of thiobarbituric acid reactive substance (TBARS) and glutathione (GSH) $[18,19]$. The second supernatant $(11,000 \mathrm{rpm}$ at $4^{\circ} \mathrm{C}$ for $15 \mathrm{~min}$ ) was used for estimation of the catalase and super oxide dismutase $[18,19]$. The total protein was also determined using the second supernatant by the method described by Lowry et al. [20].

2.7.1. Measurement of Lipid Peroxidation. The TBARS levels in the brain tissue homogenate were determined by the method described by Ohkawa et al. for estimation of lipid peroxidation in the ischemic brain [21]. To $1 \mathrm{~mL}$ of brain tissue homogenate, trichloroacetic acid $(0.5 \mathrm{~mL}, 30 \% \mathrm{w} / \mathrm{v})$ and thiobarbituric acid reagent $(0.5 \mathrm{~mL}, 0.8 \% \mathrm{w} / \mathrm{v})$ were added. The tubes were kept at a temperature of $80^{\circ} \mathrm{C}$ for $30 \mathrm{~min}$ in a shaking water bath. The tubes were centrifuged at $5000 \mathrm{rpm}$ for $10 \mathrm{~min}$ and the amount of TBARS was measured at $540 \mathrm{~nm}$ at room temperature. The blank sample contains the entire reagent in the same amount except the brain tissue homogenate. TBARS values were expressed as $n$ mol malondialdehyde/gm tissue weight.

2.7.2. Measurement of Reduced Glutathione. The calorimetric method described by Ellman was used for the estimation of GSH in brain tissue homogenate [22]. In the first step, brain homogenate and trichloroacetic acid 10\% w/v (1:1) were mixed and centrifuged at $5000 \mathrm{rpm}$ for $10 \mathrm{~min}$ to separate the proteins. To $100 \mu \mathrm{L}$ of this supernatant $5,5^{\prime}$-dithiobis nitrobenzoic acid $(500 \mu \mathrm{L})$, phosphate buffer $(\mathrm{pH} 7.4,2 \mathrm{~mL})$, and double distilled water $(0.4 \mathrm{~mL})$ were added. The mixture was vortexed and the GSH level was immediately measured at $412 \mathrm{~nm}$ against the appropriate blank and expressed as $n$ moles $\times 10^{-6} \mathrm{GSH} / \mathrm{gm}$ tissue weight.

2.7.3. Measurement of Catalase. The activity of catalase was determined by a spectrophotometric method described by Greenworld [23]. To $1.9 \mathrm{~mL}$ of phosphate buffer $(50 \mathrm{mM}, \mathrm{pH}$ 
7), a $100 \mu \mathrm{L}$ brain tissue supernatant was added to a disposable plastic cuvette and placed in spectrofluorometer. The reaction was initiated by addition of $1 \mathrm{~mL}$ of hydrogen peroxide solution $\left(\mathrm{H}_{2} \mathrm{O}_{2}, 30 \mathrm{mM}\right)$ and the decrease in absorbance of $\mathrm{H}_{2} \mathrm{O}_{2}(240 \mathrm{~nm})$ was followed. Catalase values were expressed as $n$ moles $\mathrm{H}_{2} \mathrm{O}_{2}$ consumed $/ \mathrm{min} / \mathrm{mg}$ protein.

2.7.4. Measurement of Superoxide Dismutase. The activity of superoxide dismutase was assessed by following the inhibition of pyrogallol autooxidation calorimetrically as described by Kagiyama et al. [24]. A $100 \mu \mathrm{L}$ brain tissue supernatant was added to $2900 \mu \mathrm{L}$ of Tris-HCI buffer ( $\mathrm{pH} \mathrm{8.5).} \mathrm{The}$ reaction was started with addition of pyrogallol $(25 \mu \mathrm{L})$ and the absorbance of pyrogallol was continuously measured at $420 \mathrm{~nm}$ for $15 \mathrm{~min}$. The SOD enzyme activity was expressed as $\mathrm{U} / \mathrm{mg}$ protein.

2.8. Brain and Plasma Pharmacokinetics. The brain and plasma pharmacokinetics of TQ-PLGA NPs were determined in rats as described previously $[10,11]$. Two separate groups of rats ( $n=3$ for each time point) were given TQ-PLGA NPs (equivalent to $5 \mathrm{mg} / \mathrm{kg} /$ day TQ) intravenously (by tail vein) and intranasally, respectively. The pharmacokinetic studies were continued for $72 \mathrm{~h}$ to get clear elimination phase for estimation of different pharmacokinetic parameters. Blood $(100 \mu \mathrm{L})$ was collected by tail vein in precoated heparin tubes and centrifuged for $5 \mathrm{~min}$ at $3000 \mathrm{rpm}$ to obtain the plasma $(50 \mu \mathrm{L})$ for estimation of TQ. For brain collection, rats were sacrificed at scheduled time intervals by cervical dislocation. Brain was dissected out from skull, washed, and homogenised with $2 \mathrm{~mL}$ of normal saline by a tissue homogeniser. A small aliquot of brain tissue homogenate $(200 \mu \mathrm{L})$ was used for estimation of TQ levels in brain. TQ was analyzed in plasma and brain by reverse-phase HPLC with UV detection at $254 \mathrm{~nm}$ [13]. The peak plasma concentration $\left(C_{\max }\right)$ and the time required to reach the peak plasma $\left(T_{\max }\right)$ were obtained from the brain/plasma concentration-time profile. The drug targeting efficacy (DTE\%) and nose to brain direct transport percentage (DTP\%) of the TQ-PLGA NPs after intranasal administration were calculated as follows [10]:

drug targeting efficiency (DTE\%)

$$
=\frac{(\text { AUC brain/AUC plasma }) \text { i.n. }}{\text { (AUC brain/AUC plasma) i.v. }} \times 100 \text {, }
$$

direct transport percentage (DTP\%)

$$
=\frac{D_{\text {i.n. }}-D_{z}}{D_{\text {i.n. }}} \times 100,
$$

where $D_{z}=\left(D_{\text {i.v. }} / P_{\text {i.v. }}\right) \times P_{\text {i.n. }}$ and $D_{z}$ is the brain AUC fraction contributed by systemic circulation through the BBB following intranasal administration. $D_{\text {i.v. }}, P_{\text {i.v. }}, D_{\text {i.n. }}$, and $P_{\text {i.n. }}$ correspond to the $\mathrm{AUC}_{0-72 \mathrm{~h}}$ (brain/i.v.), $\mathrm{AUC}_{0-72 \mathrm{~h}}$ (plasma/i.v.), $\mathrm{AUC}_{0-72 \mathrm{~h}}$ (brain/i.n.), and $\mathrm{AUC}_{0-72 \mathrm{~h}}$ (plasma/i.n.).

2.9. Qualitative Localization by Confocal Laser Microscopy. The qualitative localization of florescent labelled PLGA NPs was determined in brain tissues by confocal laser microscopy
(Olympus Fluoview $^{\mathrm{TM}}$, Melville, NY, USA) [25, 26]. For preparation of DAPI (4-6-diamidino-2-phenylindole) loaded PLGA nanoparticles, $0.2 \mathrm{~mL}$ of DAPI solution $(50 \mu \mathrm{g} / \mathrm{mL}$ in ethanol) was dissolved in PLGA solution and nanoparticles were prepared in similar way as described earlier. For this study, cohort of rats (normal non-MCAO rats, $n=2$ ) were given DAPI loaded PLGA NPs by intravenous and intranasal route and sacrificed at two time points, that is, after $60 \mathrm{~min}$ and $4 \mathrm{hr}$, respectively. The brain was extracted and immediately stored at $-80^{\circ} \mathrm{C}$ to prevent loss of fluorescence. On the day of experiment, coronal section $(5 \mathrm{~mm})$ of brain was made with a cryostat and analyzed with fluorescence microscope.

2.10. Statistical Analysis. All the in vivo data are expressed as mean \pm SEM. One-way analysis of variance (ANOVA) and Dunnett's " $t$ "-test were used for the comparison of different experimental groups. $P<0.05$ was considered to represent significant difference, whereas $P<0.01$ represents a highly significant difference between groups, respectively.

\section{Results}

3.1. Optimized Thymoquinone Loaded PLGA Nanoparticles. For preparation of TQ-PLGA nanoparticles, at first the blank, PLGA nanoparticles were synthesized and concentrations of polymer and stabiliser were optimized. The optimized blank nanoparticles have PLGA : CN ratio of $1: 1(\mathrm{CN}: \mathrm{PVA}=$ $1: 1)$ with particles size of $154.3 \pm 6.5 \mathrm{~nm}$ and zeta potential of $+38.56 \pm 3.32 \mathrm{mV}$. In the next step, TQ loaded PLGA nanoparticles were prepared by dissolving TQ in polymer phase (drug:polymer $0.3: 1$ ) and using the same condition/concentration as optimized for placebo nanoparticles (Table 1). The mean particles size of TQ-PLGA NPs (183.5 \pm 8.2) was found to be larger than the blank nanoparticles due to increase in the concentration of internal phase. The average zeta potential values were also found to be lower than the placebo nanoparticles due to TQ mediated increase in the net negative charge of the emulsion. Nevertheless, zeta potential value of $33.63 \pm 2.25 \mathrm{mV}$ (Table 1) represents a stable system. The PDI value of 0.257 represents narrow and unimodel particle size distribution for minimal deviation in pharmacokinetic parameters between different rats. EE\% and LC\% of the optimized TQ-PLGA NPs were found to be $73.2 \pm 2.6$ and $31.4 \pm 2.1$, respectively, which shows that TQ can be entrapped within the PLGA-CN nanoparticles. The mucin binding efficacy for optimized TQ-PLGA NPs, PLGA NPs, and TQ solution was found to be $59.6 \pm 1.5 \%, 64.0 \pm 2.7 \%$, and $2.3 \pm 0.6 \%$, respectively. Thus, the mucoadhesive strength of TQ solution was inadequate to provide sufficient nasal retention time for prolonged therapeutic effect. TQ-PLGA NPs had lower mucoadhesive strength than PLGA NPs due to reduction in their net positive charge.

Figure 1(a) shows the DSC thermograms of TQ, PLGA, TQ : PLGA mixture, and TQ-PLGA NPs. The melting point of pure TQ is $45-47^{\circ} \mathrm{C}$ and thus the endothermic peak at $\sim 45^{\circ} \mathrm{C}$ corresponds to pure TQ. PLGA polymer showed endothermic peak at $\sim 120^{\circ} \mathrm{C}$, whereas the physical mixture of TQ + PLGA retained the characteristic peaks of both 
TABLE 1: Concentration of ingredients and physiochemical parameter of the optimized thymoquinone loaded PLGA nanoparticles.

\begin{tabular}{|c|c|c|c|c|c|c|c|}
\hline $\begin{array}{l}\text { Conc. of } \\
\text { polymers }\end{array}$ & Conc. of stabiliser & $\begin{array}{c}\text { Conc. of drug } \\
(\mathrm{mg} / \mathrm{mL})\end{array}$ & $\begin{array}{c}\text { Mean particle } \\
\text { size }(\mathrm{nm} \pm \mathrm{SD})\end{array}$ & $\begin{array}{c}\text { Mean PDI } \\
( \pm \text { SD })\end{array}$ & $\begin{array}{l}\text { Zeta potential } \\
(\mathrm{mV} \pm \mathrm{SD})\end{array}$ & $\mathrm{EE} \%( \pm \mathrm{SD})$ & $\begin{array}{l}\mathrm{LC} \% \\
( \pm \mathrm{SD}) \\
\end{array}$ \\
\hline $1 \mathrm{mg} / \mathrm{mL}$ & $\begin{array}{c}0.25 \mathrm{mg} / \mathrm{mL}(\mathrm{CN}) \\
0.25 \mathrm{mg} / \mathrm{mL} \text { (PVA) }\end{array}$ & $0.3 \mathrm{mg} / \mathrm{mL}$ & $183.5 \pm 8.2$ & $0.257 \pm 0.02$ & $33.63 \pm 2.25$ & $73.2 \pm 2.6$ & $31.4 \pm 2.1$ \\
\hline
\end{tabular}

The optimized TQ-PLGA nanoparticles had PLGA : stabiliser : TQ ratio of $1: 0.5: 0.3$ with mean particle size of $183.5 \mathrm{~nm}$, polydispersity index (PDI) of 0.25 , and zeta potential of $+33.6 \mathrm{mV}$. The average encapsulation efficiency and loading capacity of TQ-PLGA nanoparticles were found to be $73.2 \%$ and $31.4 \%$, respectively.

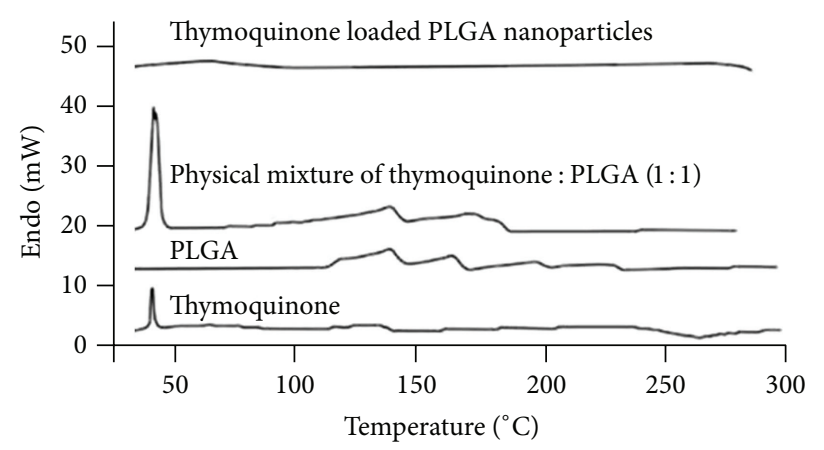

(a)

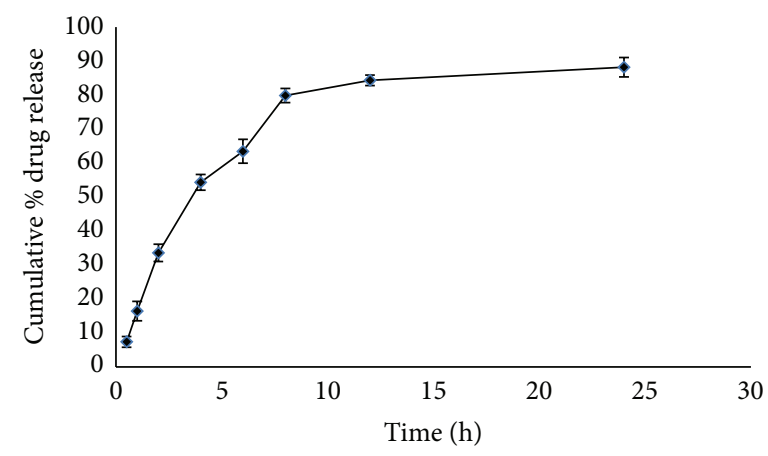

(b)

FIGURE 1: (a) DSC thermogram of TQ, PLGA, and physical mixture of TQ-PLGA and TQ loaded PLGA nanoparticles, respectively. TQ was molecularly distributed with the PLGA polymer and entrapped within PLGA-CN nanoparticle matrix; therefore the characteristic peaks of TQ $\left(45-47^{\circ} \mathrm{C}\right)$ and PLGA $\left(\sim 120^{\circ} \mathrm{C}\right)$ were not seen in TQ-PLGA nanoparticles. (b) The in vitro release of TQ-PLGA nanoparticles. It showed a biphasic release with $16 \%$ TQ release within $1 \mathrm{~h}$ followed by characteristic sustained release for more than $24 \mathrm{~h}$.

TQ and PLGA. Conversely, TQ was molecularly distributed with the PLGA polymer and entrapped within PLGA-CN nanoparticle matrix; therefore the characteristic peaks of TQ and PLGA were not seen in TQ-PLGA NPs. The in vitro release of TQ from optimized TQ-PLGA NPs (Figure 1(b)) showed a biphasic release pattern with $16 \%$ drug release within $1 \mathrm{~h}$ followed by characteristic sustained release for more than $24 \mathrm{~h}$. The cumulative percentage release of TQ from TQ-PLGA NPs was $88.21 \pm 2.872 \%$ over a period of $24 \mathrm{~h}$. The initial burst drug release was most likely due to the release of TQ loosely attached to the surface of the nanoparticles, whereas the later slow release may be due to the TQ release from the core of PLGA nanoparticles by the swelling and hydration of PLGA NPs matrix. These results showed that TQ was effectively entrapped within the PLGA NPs matrix.

\subsection{Pharmacodynamic Study and Infract Volume Measure-} ment. A significant reduction in the locomotor count $(P<$ $0.01)$ and grip strength $(P<0.05)$ was observed in the MCAO rats in comparison to the sham rats (Table 2). The difference between the locomotor count and grip strength between sham group and MCAO rats showed that ischemia symptoms were evident only after middle cerebral artery occlusion. Pretreatment with TQ-PLGA NPs (i.n.) led to significant improvement in locomotor counts and grip strength in comparison to the MCAO rats (Table 2). TQ-PLGA NPs (oral) also improved the locomotor count and grip strength but were less effective than TQ-PLGA NPs (i.n.). Similarly, TTC staining also showed a widespread infract area in MCAO rats $\left(\sim 76 \mathrm{~mm}^{3}\right)$ seven days after reperfusion (Figure 2 and Table 2). The treatment of MCAO rats with TQ-PLGA NPs (i.n.), TQ solutions (i.n.), and TQ solutions (oral) reduced the infract volume by $49.7 \%(P<0.05), 40.7 \%$, and $41.2 \%$, respectively.

3.3. Biochemical Studies. The brain lipid peroxidation was assessed by measurement of TBARS levels in all the groups 7 days after MCAO. The TBARS levels were found to be $200 \%$ higher $(P<0.01)$ in the MCAO rats in comparison to the sham rats (Figure 3). Pretreatment with TQ-PLGA NPs (i.n.) led to significant reduction in TBARS levels in the MCAO rats (Figure 2). TQ solution delivered by oral route also reduced the TBARS formation in MCAO rats but was less effective than TQ-PLGA NPs (i.n.).

GSH in the brain of MCAO rats was $42 \%$ lower than the sham control rats $(P<0.01)$. A number of publications have shown that overproduction of ROS is counter-balanced by endogenous antioxidants causing their depletion from the cells [27]. In this case endogenous GSH was consumed due to scavenging of rapidly generating free radical species in cerebral infarct. Intranasal delivery of TQ-PLGA NPs significantly elevated the glutathione levels in MCAO rats $(P<0.01)$ (Figure 4$)$. TQ solution delivered by nasal or oral route was also effective in enhancing the levels of glutathione in the MCAO rats.

The SOD and catalase activity of different groups of rats are provided in Table 3 . The catalase and SOD enzyme activity were significantly decreased in the MCAO rats in contrast to the sham control rats. Treatment with TQ-PLGA NPs 


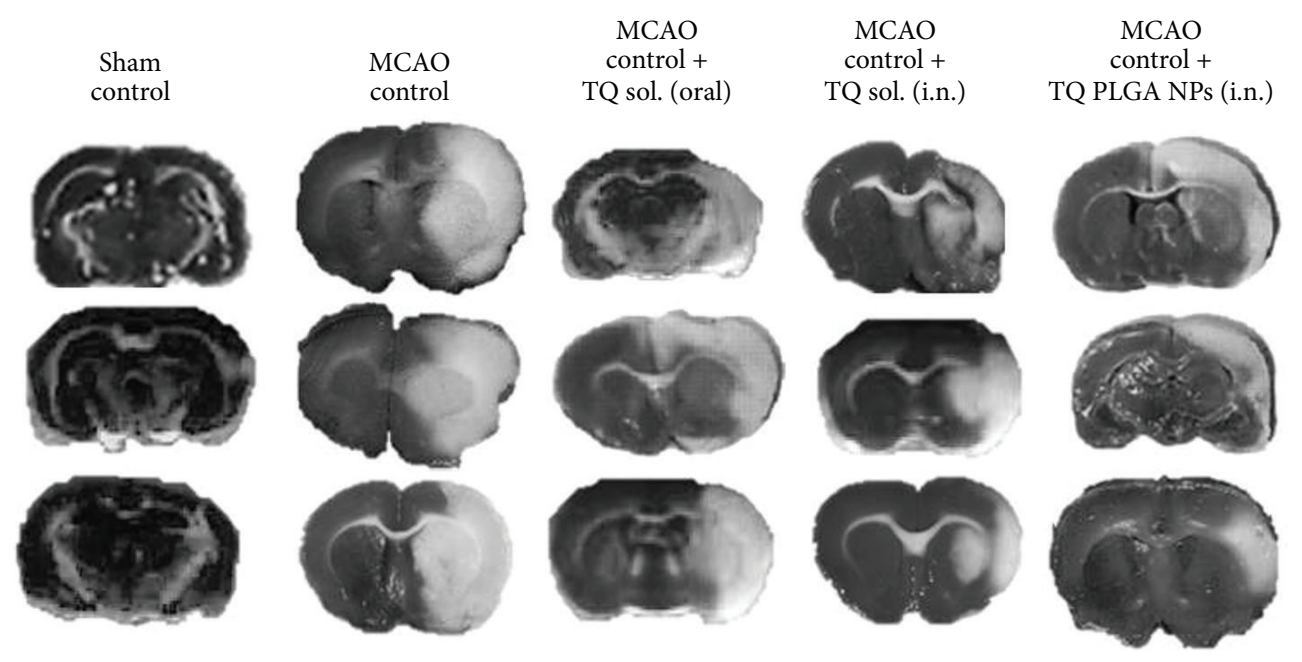

FIGURE 2: The representative images of TTC staining of different groups. The regions of the slides with the white colour are considered infracted and those with dark colour represent the healthy brain tissues. The intranasal delivery of TQ-PLGA nanoparticles led to significant reduction in infract volume in the MCAO rats when compared to TQ solution delivered by intranasal or oral route alone.

TABLE 2: Effect of thymoquinone loaded PLGA nanoparticles on locomotor activity, grip strength, and cerebral infract volume in the MCAO rats.

\begin{tabular}{|c|c|c|c|c|}
\hline Groups & Treatment & $\begin{array}{l}\text { Locomotor activity } \\
\text { (count } / 5 \mathrm{~min})\end{array}$ & $\begin{array}{l}\text { Grip strength } \\
\text { (Kg/unit) }\end{array}$ & Infarct volume $\left(\mathrm{mm}^{3}\right)^{\#}$ \\
\hline 1 & Sham control & $21.62 \pm 0.312$ & $0.68 \pm 0.053$ & - \\
\hline 2 & MCAO control & $3.54 \pm 0.021^{99}$ & $0.12 \pm 0.03^{99}$ & $76.28 \pm 0.112$ \\
\hline 3 & $\begin{array}{c}\text { MCAO + TQ } \\
\text { PLGA NPs (i.n.) }\end{array}$ & $16.89 \pm 0.218^{* *}$ & $0.36 \pm 0.087^{*}$ & $38.34 \pm 0.123^{*}$ \\
\hline 4 & $\begin{array}{l}\text { MCAO + TQ } \\
\text { solution (i.n.) }\end{array}$ & $15.12 \pm 0.093^{*}$ & $0.19 \pm 0.101$ & $45.19 \pm 0.091$ \\
\hline 5 & $\begin{array}{l}\text { MCAO + TQ } \\
\text { solution (oral) }\end{array}$ & $9.23 \pm 0.101^{*}$ & $0.23 \pm 0.214^{*}$ & $44.78 \pm 0.153$ \\
\hline
\end{tabular}

The intranasal delivery of TQ-PLGA nanoparticles led to significant increase in the locomotor activity and grip strength and decrease in ischemia infarct volume in the MCAO rats when compared to TQ solution delivered by intranasal or oral route alone. $N=12\left({ }^{\#} N=6\right)$; data represent mean \pm SEM; ${ }^{99} P<0.01$ versus sham control; ${ }^{* *} P<0.01$ versus $\mathrm{MCAO}$ control; and ${ }^{*} P<0.05$ versus MCAO control.

significantly elevated the activity of both enzymes in the MCAO rats.

3.4. Brain and Plasma Pharmacokinetics. The concentration of TQ in brain and blood plasma was determined at different time points till $72 \mathrm{~h}$ after dosing the TQ-PLGA NPs by intranasal and intravenous route, respectively (Figure 5(b)). A high brain TQ concentration was obtained when TQ-PLGA NPs were delivered by intranasal route (Figure 5(b)). Other pharmacokinetic parameters for TQ, for example, half-life, AUC, and AUMC, were found to be higher in brain for TQ-PLGA NPs (i.n.) in comparison to intravenous delivery (Figure 5(a)). Also, the rate of elimination of TQ-PLGA NPs (i.n.) was found to be significantly lower in brain (Table 4). Based on plasma AUC values, the systemic bioavailability of TQ-PLGA NPs (i.n.) was found to be $28.07 \%$. The DTE shows the average partitioning of TQ between brain and blood with time, whereas DTP stands for the percentage of TQ directly carried to the brain by nose to brain pathways. The DTE and
DTP for TQ-PLGA NPs (i.n.) were calculated to be 524.17 and 80.47 , respectively.

3.5. Qualitative Localization in Brain. The intranasal administration of DAPI-PLGA NPs showed intense blue florescence in brain due to significant role of olfactory and trigeminal pathways in nose to brain transportation of DAPI-PLGA NPs (Figure 6) [9], although the intensity of blue florescence was higher at $4 \mathrm{~h}$ than $1 \mathrm{~h}$ after dosing of DAPI-PLGA NPs (i.n.). In comparison, a low intensity of blue florescence was seen in the brain when rats were treated with DAPI loaded PLGA NPs (i.v.) due to the restriction imposed by BBB.

\section{Discussion}

The cerebral ischemia and reperfusion have been reported to elevate the free radical production in brain tissues and lead to substantial alterations in the level as well as activity of endogenous antioxidant enzymes $[2,3]$, whereas in normal 
TABLE 3: Effect of thymoquinone loaded PLGA nanoparticles on the catalase and SOD activity in the brain of MCAO rats.

\begin{tabular}{lccc}
\hline Groups & Treatment & $\begin{array}{c}\text { Catalase } \\
\left(n \text { moles of } \mathrm{H}_{2} \mathrm{O}_{2} / \mathrm{min} / \mathrm{mg} \text { protein }\right)\end{array}$ & $7.30 \pm 0.031$ \\
\hline 1 & Sham control & $3.81 \pm 0.112$ & $4.53 \pm 0.311^{\mathbf{9 g}}$ \\
2 & MCAO control & $1.54 \pm 0.106^{\mathbf{9 9}}$ & $7.01 \pm 0.078^{* *}$ \\
3 & MCAO + TQ PLGA NPs (i.n.) & $3.64 \pm 0.054^{*}$ & $5.57 \pm 0.031^{*}$ \\
4 & MCAO + TQ solution (i.n.) & $2.06 \pm 0.018$ & $5.49 \pm 0.084^{*}$ \\
5 & MCAO + TQ solution (oral) & $1.96 \pm 0.021$ & \\
\hline
\end{tabular}

The intranasal delivery of TQ-PLGA nanoparticles led to significant increase in the antioxidant enzymes catalase and SOD in the MCAO rats when compared to TQ solution delivered by intranasal or oral route alone. $N=6$; data represent mean \pm SEM; ${ }^{99} P<0.01$ versus sham control; ${ }^{* *} P<0.01$ versus MCAO control; and ${ }^{*} P<0.05$ versus $\mathrm{MCAO}$ control.

TABLE 4: Brain and plasma pharmacokinetic parameters of thymoquinone loaded PLGA nanoparticles after intravenous and intranasal delivery.

\begin{tabular}{|c|c|c|c|c|c|c|c|}
\hline Formulation & Organ/tissue & $\begin{array}{c}\text { Peak } \\
\text { plasma conc. } \\
\left(C_{\max }\right) \\
(\mathrm{ng} / \mathrm{mL})\end{array}$ & $\begin{array}{l}\text { Time peak } \\
\text { plasma conc. } \\
\left(T_{\max }\right) \\
(\mathrm{h})\end{array}$ & $\begin{array}{l}\text { Half-life } \\
\left(T_{1 / 2}\right) \\
(\mathrm{h})\end{array}$ & $\begin{array}{c}\text { Rate of } \\
\text { elimination } \\
\left(K_{e}\right) \\
\left(h^{-1}\right) \\
\end{array}$ & $\begin{array}{l}\mathrm{AUC}_{0-72 \mathrm{~h}} \\
\left(\mathrm{ng} \mathrm{mL}^{-1} \mathrm{~h}\right)\end{array}$ & $\begin{array}{c}\mathrm{AUC}_{0-\infty} \\
\left(\mathrm{ng} \mathrm{mL} \mathrm{mL}^{-1} \mathrm{~h}\right)\end{array}$ \\
\hline \multirow{2}{*}{$\begin{array}{l}\text { TQ-PLGA NPs } \\
\text { (i.v.) }\end{array}$} & Brain & $390.61 \pm 54.44$ & 8 & $18.11 \pm 1.97$ & $0.010 \pm 0.003$ & $11204.3 \pm 3211.6$ & $20296.3 \pm 3265.6$ \\
\hline & Plasma & $15897.67 \pm 3443.52$ & - & $62.34 \pm 7.04$ & $0.038 \pm 0.004$ & $312654.2 \pm 6542.6$ & $351453.2 \pm 14915.1$ \\
\hline \multirow{2}{*}{$\begin{array}{l}\text { TQ-PLGA NPs } \\
\text { (i.n.) }\end{array}$} & Brain & $996.43 \pm 119.36$ & 12 & $118.23 \pm 3.97$ & $0.005 \pm 0.000$ & $33771.2 \pm 994.5$ & $98675.6 \pm 8157.1$ \\
\hline & Plasma & $3465.33 \pm 664.16$ & 4 & $194.24 \pm 9.87$ & $0.003 \pm 0.000$ & $142315.1 \pm 33217.3$ & $359773.4 \pm 44132.3$ \\
\hline
\end{tabular}

$N=3$; data represent mean \pm SEM.

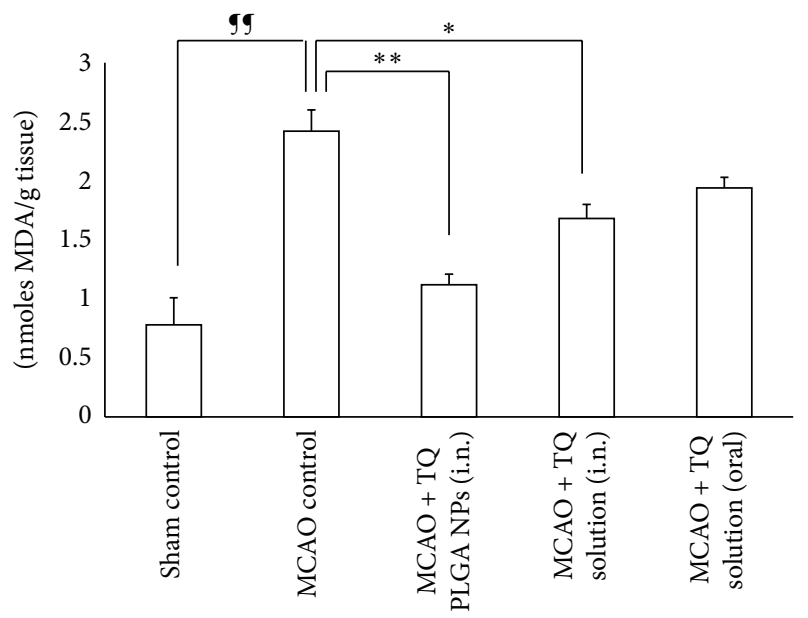

FIGURE 3: Effect of TQ loaded PLGA nanoparticles on TBARS level in the brain of MCAO rats. The intranasal delivery of TQ-PLGA nanoparticles led to significant reduction in TBARS levels in the MCAO rats when compared to TQ solution delivered by intranasal or oral route alone $\left(N=6\right.$; data represent mean $\pm \mathrm{SEM} ;{ }^{99} \mathrm{P}<0.01$ versus sham control; ${ }^{* *} P<0.01$ versus MCAO control; and ${ }^{*} P<$ 0.05 versus $\mathrm{MCAO}$ control).

brain tissues free radical species and ROS are neutralized by endogenous enzymatic and nonenzymatic antioxidants $[2,3]$. ROS species, for example, superoxide, hydroxyl, and peroxynitrite radical, have established role in peroxidation of cell membrane lipids $[2,3,27]$. Oxidative stress by brain ischemia has been found to encourage the synthesis of peroxynitrite, a powerful free radical species capable of inducing severe lipid

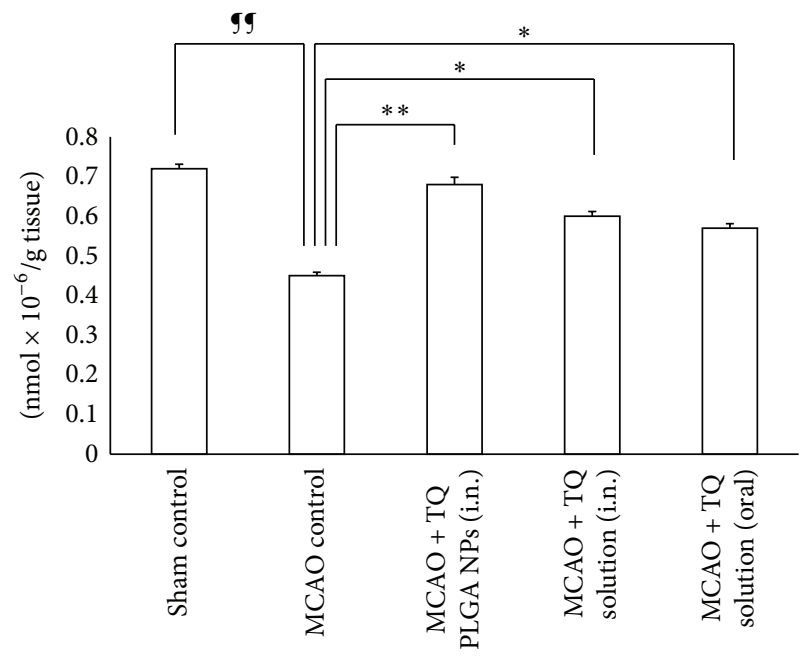

FIGURE 4: Effect of TQ loaded PLGA nanoparticles on glutathione level in the brain of MCAO rats. The intranasal delivery of TQ-PLGA nanoparticles led to significant elevation in the GSH levels in the MCAO rats when compared to TQ solution delivered by intranasal or oral route alone $\left(N=6\right.$; data represent mean \pm SEM; ${ }^{99} P<0.01$ versus sham control; ${ }^{* *} P<0.01$ versus MCAO control; and ${ }^{*} P<$ 0.05 versus $\mathrm{MCAO}$ control).

peroxidation and cellular damage to the brain [28]. Brain tissues are more prone towards oxidative injury due to their high polyunsaturated fatty acids content and low repair mechanism together with nonreplicating nature of neuron [4]. TQ is a hydrophobic phytochemical and many natural hydrophobic phytochemicals delivered by oral route have been found to 


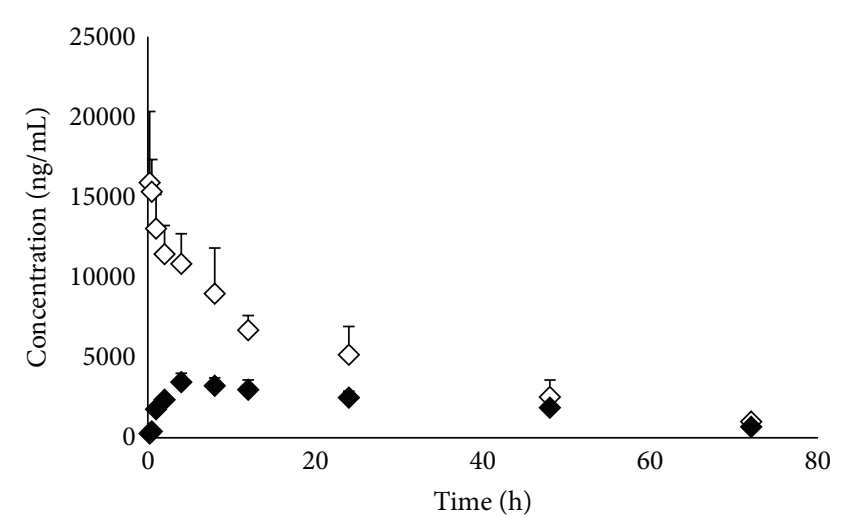

(a) Plasma concentration

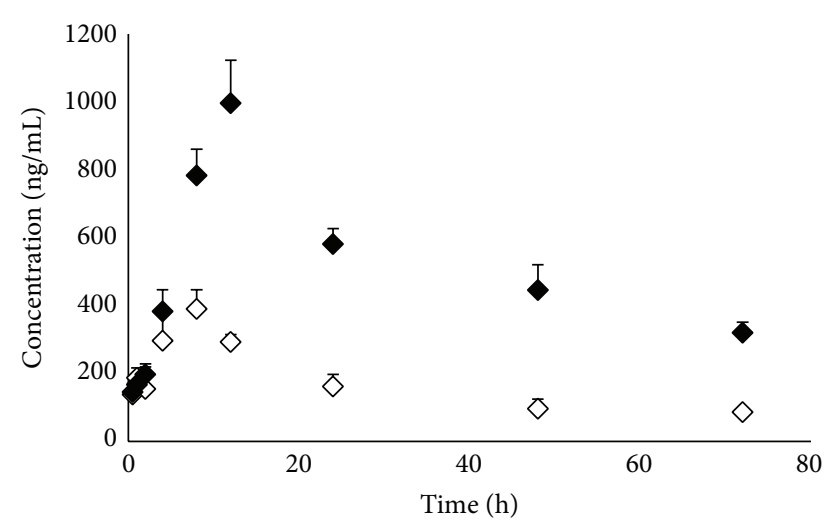

(b) Brain concentration

FIGURE 5: Brain and plasma levels of TQ following the administration of TQ loaded PLGA nanoparticles by (a) intravenous route (white diamonds) and (b) intranasal route (black diamonds). The intranasal delivery of TQ-PLGA nanoparticles led to higher brain concentration but lower plasma concentration of TQ when compared with intravenous delivery $(N=3$; data represent mean \pm SEM).

have low plasma bioavailability and poor permeability across intestinal tract [29]. In a recent report by Alkharfy and colleagues, TQ was reported to have very slow absorption but rapid elimination following oral delivery [30]. They further reported the absolute bioavailability of TQ to be $<60 \%$ of the administered dose with $>99 \%$ plasma protein binding [30]. Therefore, intranasal nose to brain route represents a better strategy for noninvasive delivery of TQ to the brain. The literature suggests that an intranasally administered therapeutic agent reaches the brain by a number of extracellular and intracellular mechanisms by olfactory and trigeminal nerve pathways $[10,11]$. A number of studies have comprehensively shown that mucoadhesive nanoparticles can transport the enclosed drugs to the brain by unique nose to brain transportation pathways and maintain effective therapeutic concentration beyond $48 \mathrm{~h}$ in the brain [9-11]. Therefore, TQ was encapsulated in polymeric nanoparticles composed of PLGA and CN. Nanoparticulate drug delivery systems have been documented to have higher potential in treatment of ischemic stroke and, potentially, other neurologic disorders. For instance, Joachim et al. showed that gelatin nanoparticle improved the neuroprotection of intranasally delivered osteopontin in rat ischemic stroke model [31]. In a recent study, it was shown that intranasal delivery of PNIPAM nanoformulation of curcuminoids reduced oxidative stressassociated brain injury after middle cerebral artery occlusion [32]. Zhao et al. reported that intranasal delivery of gelatin nanoparticle loaded with neuropeptide substance $P$ enhanced the neurorecovery in hemiparkinsonian rats [33]. Nagai et al. showed that intravenous administration of cilostazol nanoparticles ameliorates acute ischemic stroke in a cerebral ischemia/reperfusion-induced injury model [34]. Consistent with these findings, pretreatment with TQ-PLGA NPs (i.n.) improved the locomotor activity and grip strength in the MCAO rats with reversal of ischemic infarct in the brain. TQ and its active metabolite thymohydroquinone have been found to inhibit the lipid peroxidation as they scavenge the superoxide, hydroxyl radical, and singlet molecular oxygen $[5,6]$. Beside this, TQ has also been reported to restrain the arachidonic acid metabolism and prevent the ischemic brain damage from metabolic products formed by inflammatory cyclooxygenase and lipoxyegnase pathways [35]. Therefore, pretreatment with TQ-PLGA NPs led to reversal in the TBARS and GSH level in the MCAO rats. The potency of the reversal in the GSH and TBARS level was strongly dependent on the uninterrupted availability of TQ at the site of ischemia infract, which explains the superior protective and therapeutic effect of TQ-PLGA NPs (i.n.) in comparison to other formulations $[5,18]$. These observations are in harmony with the previous publications which have comprehensively shown that treatment with TQ rescued the neurons from ischemic death and offered protection against cerebral ischemia $[5,6,18,19]$. Although, like previous studies, we also observed improvement in the pharmacodynamic and biochemical profile after oral administration of TQ, the results were inferior in comparison to TQ-PLGA NPs (i.n.) $[5,18,19]$. Mucociliary clearance as well as low mucoadhesive strength of the TQ solution led to its rapid clearance from the nasal cavity and diminished therapeutic activity [10, 11]. The pharmacokinetic studies showed that the intranasal administration of TQ-PLGA NPs facilitated the delivery of TQ to brain and increased its brain concentration for a prolonged period of time with simultaneous improvement in other pharmacokinetic parameters in brain. The high mucoadhesive strength of PLGA-CN nanoparticles increased the retention time of TQ in the nasal cavity to sustain effective therapeutic concentration in brain. In addition, $\mathrm{CN}$ used in nose to brain formulations have been found to enhance the paracellular transport through epithelial tight junctions due to their specific interaction with the protein kinase $\mathrm{C}$ pathway or electrostatic interaction with negative charged sialic acid residues on mucosal epithelial cells [36]. Several studies have shown that NPs smaller than $200 \mathrm{~nm}$ are easily transported through olfactory membrane transcellularly by olfactory neurones to the brain and the results of qualitative localization study in brain tissues with DAPI loaded PLGA nanoparticles (i.n.) are consistent with these findings [911]. Thus, PLGA-CN nanoparticles improved the delivery 

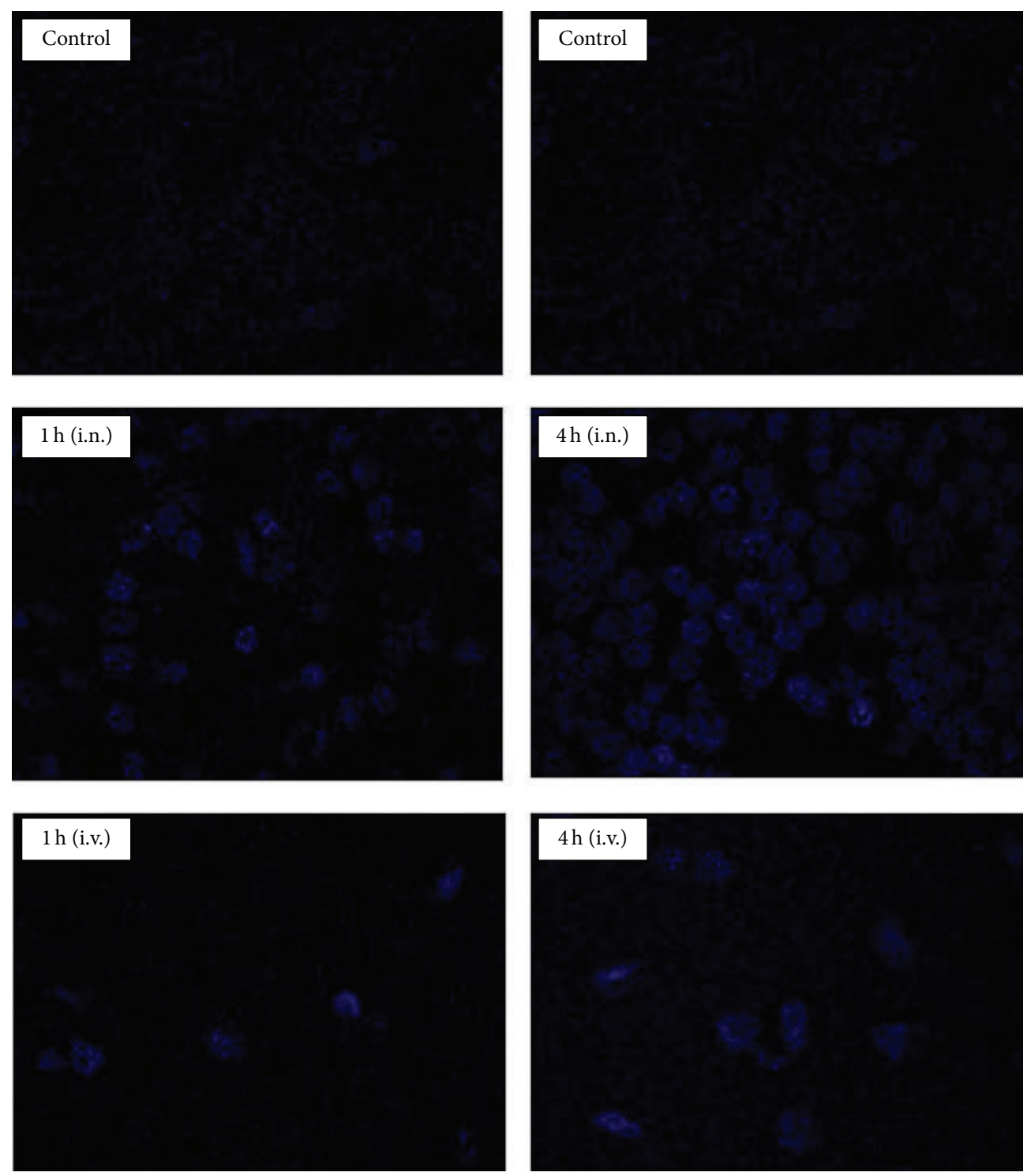

FIGURE 6: Qualitative localization of DAPI loaded PLGA nanoparticles in brain tissues after intranasal (i.n.) and intravenous (i.v.) administration at $1 \mathrm{~h}$ and $4 \mathrm{~h}$, respectively, after dosing. A higher proportion of DAPI stained brain cells were seen when DAPI loaded PLGA nanoparticles were administered by i.n. route in comparison to i.v. route.

of TQ to brain which potentiated its neuroprotective and therapeutic effect against cerebral ischemia.

\section{Conclusion}

Cerebral ischemia is one the most challenging CNS diseases as there is a large clinical variability in terms of severity of ischemia, localization, and duration with limited treatment options. In the current study, nose to brain delivery of optimized thymoquinone loaded PLGA nanoparticles enhanced the pharmacokinetic profile of thymoquinone in brain and effectively reversed the symptoms of cerebral ischemia as well as rescuing the brain cells from ischemic death in rats by virtue of their antioxidant and free radical scavenging properties. Thus, antioxidant therapy with novel nanomedicine and new route of administration (i.e., nose to brain delivery) can be potentially used for neuroprotection and treatment of cerebral ischemia. However, these novel nanomedicines require rigorous preclinical studies for their toxicity, pharmacokinetics, and pharmacodynamics in higher animal models for possible human clinical application.

\section{Competing Interests}

The authors declare that they have no competing interests.

\section{Authors' Contributions}

Xiao-Yu Xiao and Ying-Xian Zhu contributed equally to this work. 


\section{Acknowledgments}

This research work was supported by the grant from the Zhuhai Municipal Science and Technology Plan (2015A1010).

\section{References}

[1] C. J. L. Murray and A. D. Lopez, "Global mortality, disability, and the contribution of risk factors: Global Burden of Disease Study," The Lancet, vol. 349, no. 9063, pp. 1436-1442, 1997.

[2] E. Candelario-Jalil, N. H. Mhadu, S. M. Al-Dalain, G. Martínez, and O. S. León, "Time course of oxidative damage in different brain regions following transient cerebral ischemia in gerbils," Neuroscience Research, vol. 41, no. 3, pp. 233-241, 2001.

[3] B. Schaller and R. Graf, "Cerebral ischemia and reperfusion: the pathophysiologic concept as a basis for clinical therapy," Journal of Cerebral Blood Flow \& Metabolism, vol. 24, no. 4, pp. 351-371, 2004.

[4] C. Bromont, C. Marie, and J. Bralet, "Increased lipid peroxidation in vulnerable brain regions after transient forebrain ischemia in rats," Stroke, vol. 20, no. 7, pp. 918-924, 1989.

[5] A. A. Al-Majed, F. A. Al-Omar, and M. N. Nagi, "Neuroprotective effects of thymoquinone against transient forebrain ischemia in the rat hippocampus," European Journal of Pharmacology, vol. 543, no. 1-3, pp. 40-47, 2006.

[6] M. Kanter, "Nigella sativa and derived thymoquinone prevents hippocampal neurodegeneration after chronic toluene exposure in rats," Neurochemical Research, vol. 33, no. 3, pp. 579-588, 2008.

[7] W. M. Pardridge, "The blood-brain barrier: bottleneck in brain drug development," NeuroRx, vol. 2, no. 1, pp. 3-14, 2005.

[8] A. Pires, A. Fortuna, G. Alves, and A. Falcão, "Intranasal drug delivery: how, why and what for?" Journal of Pharmacy and Pharmaceutical Sciences, vol. 12, no. 3, pp. 288-311, 2009.

[9] L. Illum, "Transport of drugs from the nasal cavity to the central nervous system," European Journal of Pharmaceutical Sciences, vol. 11, no. 1, pp. 1-18, 2000.

[10] M. Kumar, A. Misra, A. K. Babbar, A. K. Mishra, P. Mishra, and K. Pathak, "Intranasal nanoemulsion based brain targeting drug delivery system of risperidone," International Journal of Pharmaceutics, vol. 358, no. 1-2, pp. 285-291, 2008.

[11] S. Haque, S. Md, M. Fazil et al., "Venlafaxine loaded chitosan NPs for brain targeting: pharmacokinetic and pharmacodynamic evaluation," Carbohydrate Polymers, vol. 89, no. 1, pp. 7279, 2012.

[12] Y. Wang, P. Li, and L. Kong, "Chitosan-modified PLGA nanoparticles with versatile surface for improved drug delivery," AAPS PharmSciTech, vol. 14, no. 2, pp. 585-592, 2013.

[13] O. A. Ghosheh, A. A. Houdi, and P. A. Crooks, "High performance liquid chromatographic analysis of the pharmacologically active quinones and related compounds in the oil of the black seed (Nigella sativa L.)," Journal of Pharmaceutical and Biomedical Analysis, vol. 19, no. 5, pp. 757-762, 1999.

[14] Y. Yin, D. Chen, M. Qiao, Z. Lu, and H. Hu, "Preparation and evaluation of lectin-conjugated PLGA nanoparticles for oral delivery of thymopentin," Journal of Controlled Release, vol. 116, no. 3, pp. 337-345, 2006.

[15] E. Z. Longa, P. R. Weinstein, S. Carlson, and R. Cummins, "Reversible middle cerebral artery occlusion without craniectomy in rats," Stroke, vol. 20, no. 1, pp. 84-91, 1989.

[16] A. Durukan and T. Tatlisumak, "Acute ischemic stroke: overview of major experimental rodent models, pathophysiology, and therapy of focal cerebral ischemia," Pharmacology Biochemistry and Behavior, vol. 87, no. 1, pp. 179-197, 2007.

[17] J. B. Bederson, L. H. Pitts, S. M. Germano, M. C. Nishimura, R. L. Davis, and H. M. Bartkowski, "Evaluation of 2,3,5triphenyltetrazolium chloride as a stain for detection and quantification of experimental cerebral infarction in rats," Stroke, vol. 17, no. 6, pp. 1304-1308, 1986.

[18] M. Akhtar, A. M. Maikiyo, A. K. Najmi, R. Khanam, M. Mujeeb, and M. Aqil, "Neuroprotective effects of chloroform and petroleum ether extracts of Nigella sativa seeds in stroke model of rat," Journal of Pharmacy and Bioallied Sciences, vol. 5, no. 2, pp. 119-125, 2013.

[19] M. Akhtar, A. M. Maikiyo, R. Khanam, M. Mujeeb, M. Aqil, and A. K. Najmi, "Ameliorating effects of two extracts of Nigella sativa in middle cerebral artery occluded rat," Journal of Pharmacy and Bioallied Sciences, vol. 4, no. 1, pp. 70-75, 2012.

[20] O. H. Lowry, N. J. Rosebrough, A. L. Farr, and R. J. Randall, "Protein measurement with the Folin phenol reagent," The Journal of Biological Chemistry, vol. 193, no. 1, pp. 265-275, 1951.

[21] H. Ohkawa, N. Ohishi, and K. Yagi, "Assay for lipid peroxides in animal tissues by thiobarbituric acid reaction," Analytical Biochemistry, vol. 95, no. 2, pp. 351-358, 1979.

[22] G. L. Ellman, "Tissue sulfhydryl groups," Archives of Biochemistry and Biophysics, vol. 82, no. 1, pp. 70-77, 1959.

[23] R. A. Greenworld, CRC Handbook of Methods for Oxygen Radical Research, CRC Press, Boca Raton, Fla, USA, 1985.

[24] T. Kagiyama, S. Kagiyama, and M. I. Phillips, "Expression of angiotensin type 1 and 2 receptors in brain after transient middle cerebral artery occlusion in rats," Regulatory Peptides, vol. 110, no. 3, pp. 241-247, 2003.

[25] G. Tosi, L. Costantino, F. Rivasi et al., "Targeting the central nervous system: in vivo experiments with peptide-derivatized nanoparticles loaded with Loperamide and Rhodamine-123," Journal of Controlled Release, vol. 122, no. 1, pp. 1-9, 2007.

[26] G. Mustafa, A. Ahuja, A. H. Al Rohaimi et al., "Nanoropinirole for the management of Parkinsonism: blood-brain pharmacokinetics and carrier localization," Expert Review of Neurotherapeutics, vol. 15, no. 6, pp. 695-710, 2015.

[27] K. Rahman, "Studies on free radicals, antioxidants, and cofactors," Clinical Interventions in Aging, vol. 2, no. 2, pp. 219-236, 2007.

[28] P. Pacher, J. S. Beckman, and L. Liaudet, "Nitric oxide and peroxynitrite in health and disease," Physiological Reviews, vol. 87, no. 1, pp. 315-424, 2007.

[29] M.-J. R. Howes and P. J. Houghton, "Plants used in Chinese and Indian traditional medicine for improvement of memory and cognitive function," Pharmacology Biochemistry and Behavior, vol. 75, no. 3, pp. 513-527, 2003.

[30] K. M. Alkharfy, A. Ahmad, R. M. A. Khan, and W. M. AlShagha, "Pharmacokinetic plasma behaviors of intravenous and oral bioavailability of thymoquinone in a rabbit model," European Journal of Drug Metabolism and Pharmacokinetics, vol. 40, no. 3, pp. 319-323, 2015.

[31] E. Joachim, I.-D. Kim, Y. Jin, K. Kim, J.-K. Lee, and H. Choi, "Gelatin nanoparticles enhance the neuroprotective effects of intranasally administered osteopontin in rat ischemic stroke model," Drug Delivery and Translational Research, vol. 4, no. 56, pp. 395-399, 2014.

[32] N. Ahmad, S. Umar, M. Ashafaq et al., "A comparative study of PNIPAM nanoparticles of curcumin, demethoxycurcumin, and bisdemethoxycurcumin and their effects on oxidative stress 
markers in experimental stroke," Protoplasma, vol. 250, no. 6, pp. 1327-1338, 2013.

[33] Y. Zhao, R. Jin, W. Yang et al., "Using gelatin nanoparticle mediated intranasal delivery of neuropeptide substance $\mathrm{P}$ to enhance neuro-recovery in hemiparkinsonian rats," PLOS ONE, vol. 11, no. 2, Article ID e0148848, 2016.

[34] N. Nagai, C. Yoshioka, Y. Ito, Y. Funakami, H. Nishikawa, and A. Kawabata, "Intravenous administration of cilostazol nanoparticles ameliorates acute ischemic stroke in a cerebral ischemia/reperfusion-induced injury model," International Journal of Molecular Sciences, vol. 16, no. 12, pp. 29329-29344, 2015.

[35] R. El Mezayen, M. El Gazzar, M. R. Nicolls, J. C. Marecki, S. C. Dreskin, and H. Nomiyama, "Effect of thymoquinone on cyclooxygenase expression and prostaglandin production in a mouse model of allergic airway inflammation," Immunology Letters, vol. 106, no. 1, pp. 72-81, 2006.

[36] A. M. Dyer, M. Hinchcliffe, P. Watts et al., "Nasal delivery of insulin using novel chitosan based formulations: a comparative study in two animal models between simple chitosan formulations and chitosan nanoparticles," Pharmaceutical Research, vol. 19, no. 7, pp. 998-1008, 2002. 

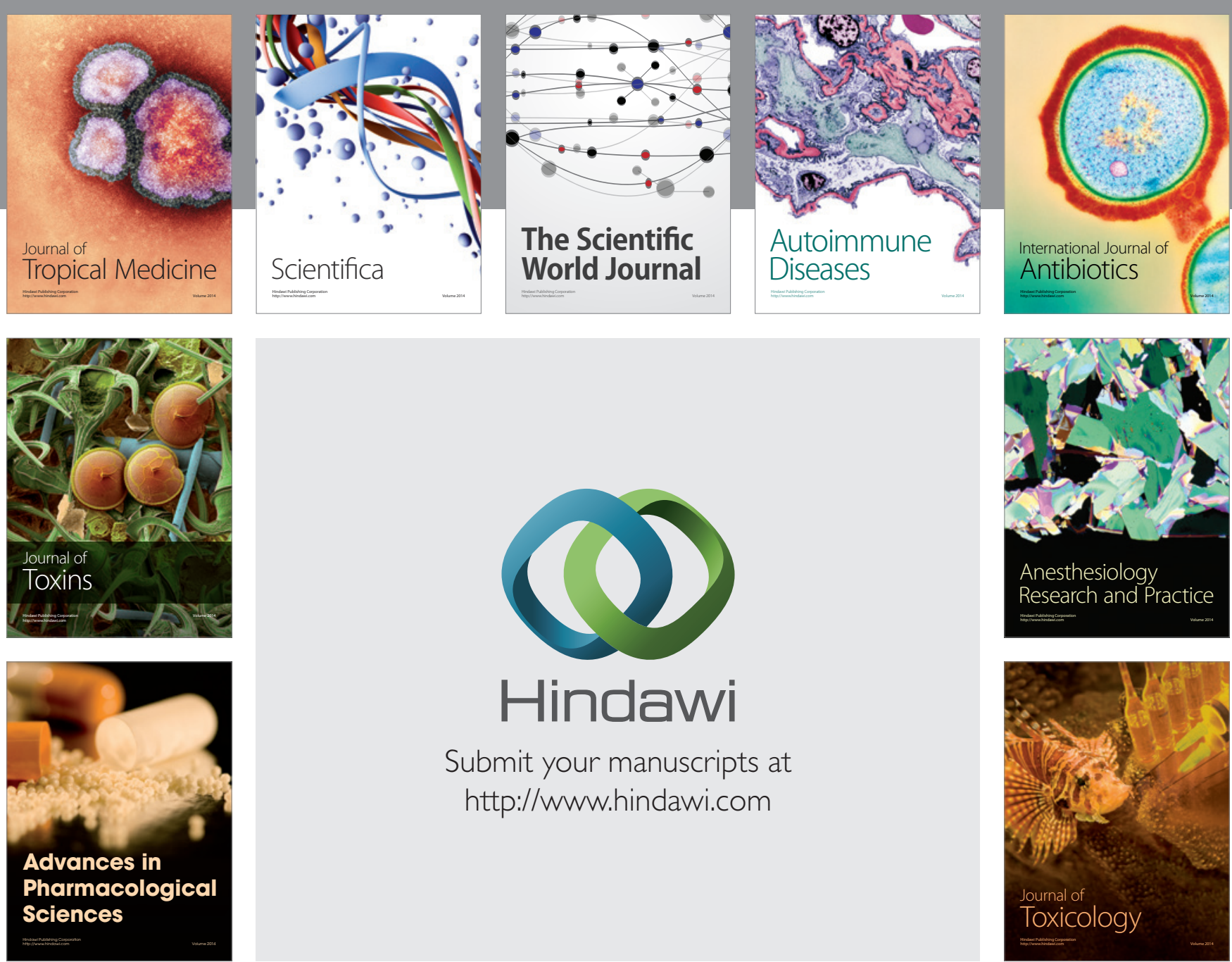

\section{Hindawi}

Submit your manuscripts at

http://www.hindawi.com
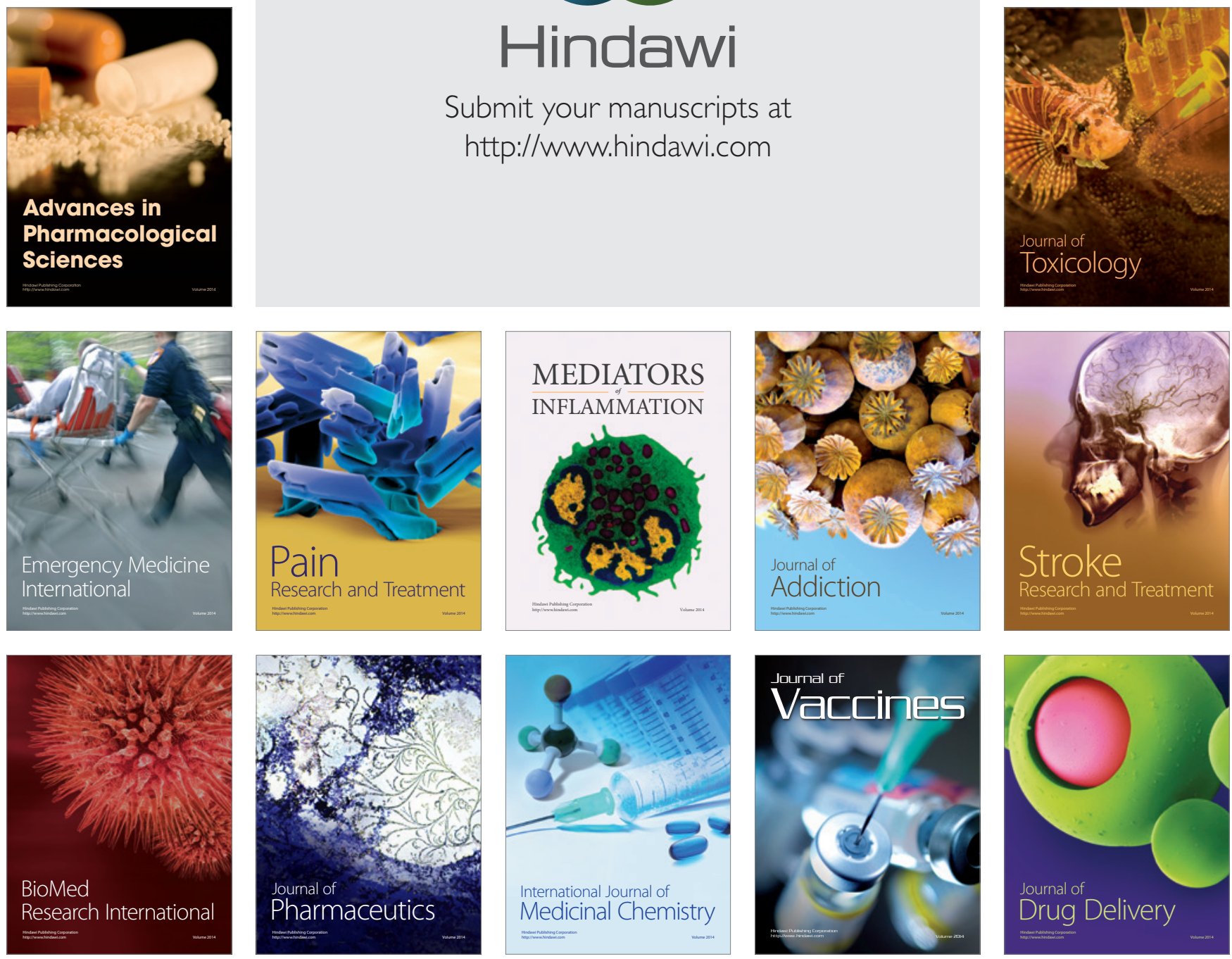